\title{
HHV-6, Not JC Virus, Causes Demyelination in PML Connections Between HHV-6, HIV-1 and JC Virus in Multiple Sclerosis, Neuro-AIDS and PML A Commentary and Review Offering Guidelines for Treatment
} Benjamin M Blumberg*

Department of Neurology, Microbiology and Immunology, University of Rochester Medical School, NY, USA

*Corresponding author: Benjamin M Blumberg Formerly Associate Professor, Department of Neurology, Microbiology and Immunology, University of Rochester Medical School, 6 Horizon Rd, Apt 2302, Fort Lee, NJ, 07024, USA, Tel: +1 585-275-2100; E-mail: bbrl@aol.com

Rec date: Sep 02, 2016; Acc date: Sep 06, 2016; Pub date: Sep 08, 2016

Copyright: () 2016 Blumberg BM. This is an open-access article distributed under the terms of the Creative Commons Attribution License, which permits unrestricted use, distribution, and reproduction in any medium, provided the original author and source are credited.

\begin{abstract}
In recent years, two outstandingly effective drugs for the treatment of multiple sclerosis (MS) have appeared on the market: Tysabri® (Biogen Idec/Elan, 2008) and Gilenya ${ }^{\circledR}$ (Novartis, 2010). Tysabri (Natalizumab) is a humanized monoclonal antibody that binds to the cellular adhesion molecule alpha- 4 integrin, which is used by lymphocytes to cross vascular walls and penetrate the blood-brain barrier. Tysabri thus reduces the flux of infected or autoimmune lymphocytes into the CNS. Gilenya (Fingolimod) is an immunomodulatory drug that acts on the sphingosine-1-phosphate receptor to sequester lymphocytes in peripheral lymph nodes, thus also indirectly reducing the flux of infected or autoimmune lymphocytes into the CNS. Both drugs have great clinical promise for treating MS, but both have revealed a critical shortcoming: their use increases the risk of Progressive Multifocal Leucoencephalopathy (PML), a demyelinating disease worse than MS and quickly fatal if not controlled. PML arises in individuals whose immune function is compromised, such as patients undergoing chemotherapy for various kinds of cancer. During the early years of the AIDS epidemic (approximately from 1986-1999), the incidence of PML rose in parallel with increasing numbers of immunocompromised AIDS patients, then fell after effective combined aggressive retrovirus treatment (CART) for HIV-1/AIDS became widely available (after 2000-2001). Unfortunately, the incidence of PML is now rising again in conjunction with the increased use of Tysabri and Gilenya in treating MS. It is therefore important to identify effective treatment modalities for PML.
\end{abstract}

Keywords: Progressive multifocal leukoencephalopathy (PML); Multiple Sclerosis; Neuro-AIDS; Treatment; Clinical promise

\section{Introduction}

Between 1994 and 2006, before Tysabri or Gilenya appeared on the market, I and a group of colleagues at the University of Rochester performed a series of neuropathological studies, first on HIV-1 in pediatric AIDS brain tissues, then on HIV-1 and human herpesvirus-6 (HHV-6) in pediatric and adult AIDS brain tissues, with MS and other neurological disease brain samples used as controls, and finally on the "holy trio" of HIV-1, HHV-6 and JC virus, in these same samples, and also in samples of PML brain tissue as suggested by Dr. David J Mock in my laboratory. Our findings were presented in eight papers [1-8], but these papers seem never to be cited anymore. As an ensemble, these papers demonstrate that HHV-6 is the demyelinating agent in MS, and also that HHV-6, not JC virus, is the true demyelinating agent in PML. In this paper I review the data that underlie this view, in the hope that by using a more inflammatory title I may call attention to the seemingly forgotten role of HHV-6 in PML, and offer some new guidelines for treatment of MS and PML patients who are receiving Tysabri or Gilenya.

\section{A Brief History of JC virus and HHV-6 in PML}

The JC (John Cunningham) polyomavirus has been identified as the cause of PML for decades [9-12], and every recent (2009 and later) chapter in medical texts and every recent relevant research and review paper that I have seen reflexively cites only JC virus as the cause of
PML. However, my work on pediatric neuro-AIDS (performed in 1998-2006) revealed that although JC virus is certainly necessary for PML to occur, it does not cause the debilitating demyelination characteristic of PML. That job is actually done by HHV-6, which does not stand out in epidemiological studies because HHV-6 is universally acquired (prevalence over 90\%) by two years of age [13,14], in contrast to JC virus which is generally acquired in late childhood, with a prevalence of around $50 \%$ at age 12 [15], and thus does stand out in epidemiological studies. In contrast to JC virus, HHV-6 is a relative newcomer to the field of virology. It was discovered in 1986 in the laboratory of Robert Gallo [16], whose pioneering use of IL-2 in tissue culture enabled the discovery of both HIV-1 and Herpesviruses -6, -7 and -8 . HHV-6 was originally called HTLV-X and was thought of mostly as a virus of lymphocytes. Later studies showed that HHV-6 was perhaps the most prevalent herpesvirus in the brain, where it displays a very strong tropism for oligodendrocytes $[17,18]$.

\section{Our Studies on HIV-1 in Pediatric Aids Brain}

My first experience in the techniques of neuropathology came in conjunction with a sensitive two-step method for in situ PCR in formalin-fixed, paraffin-embedded tissue sections, that I pioneered $[19,20]$. The "tricks" in this technique consisted of slow thermocycling with multiple primer sets for HIV-1 genes and controls using digoxigenin-labelled dUTP in the in situ PCR reaction, followed by in situ hybridization with biotin-labelled probes produced by ordinary solution PCR. In this technique, the slow thermocycling allowed good penetration of the PCR reagents into the proteinacous mesh of formalin-fixed tissue; the hydrophobic digoxigenin-dUTP molecule 
was used to help anchor the PCR product in the tissue, rather than for labelling the target, while the biotinylated probes provided specificity. Signal was then developed using ordinary avidin-biotin immunocytochemistry. Although some criticized this technique at the time, over the years I found that it provided good specificity and sensitivity on the order of a few target copies per cell.

The first application of this technique was to identify HIV-1 infected cells in the brains of children who died with severe HIV-1 encephalitis, supplied by Dr. Leroy Sharer. At this time, it was thought that productively infected cells of monocyte origin such as microglia, macrophages and multinucleated giant cells (MGCs) were the only cells infected by HIV-1 in the brain. By two-step ISPCR we found that astrocytes and perineuronal satellite cells of glial origin were also infected, but not neurons or oligodendrocytes $[19,20]$. Turning our attention to HIV-1 infection of astrocytes, we found by in situ hybridization and immunocytochemistry for the HIV-1 NEF accessory gene and protein, that HIV-1 did indeed infect large numbers of astrocytes, but that this infection was of an unusual type that I termed "restricted" infection, where the nef gene was overexpressed but the structural genes associated with productive infection, such as gag or env, were not expressed at a detectable level [21].

\section{Our Studies on HIV-1 and HHV-6 in AIDS and MS Brain Tissues}

Since I was in a Department of Pediatric Neurology, and since one of our collaborating groups was headed by Dr. Caroline Breese Hall, whose father had identified HHV-6 as the causative agent of exanthem subitum (roseola) in infants, and since HHV-6 was present in essentially $100 \%$ of all pediatric brains, my boss at the time, Dr. Leon Epstein, had the reasonable idea that in children with AIDS, the HHV-6 virus might stimulate HIV-1 in the brain, as it does in lymphocytes $[22,23]$ and exacerbate the neurological deficits associated with HIV-1 in children. We therefore used in situ hybridization combined with immunocytochemistry to determine whether HHV-6 co-localized with HIV-1 in AIDS and control brain tissues [1]. The results showed that HHV-6 DNA and proteins were found in numerous oligodendrocytes of the white matter, and less frequently in astrocytes, macrophages, microglia and neurons of children with HIV-1/AIDS, but that active HHV-6 infection was much less frequent in control tissues from immunocompetent children without HIV-1 infection, and was entirely lacking in fetal brain tissues. We concluded that HHV-6 "is more extensively disseminated in neural cells in the presence of HIV-1 infection and immunodeficiency in children, and could contribute to the pathogenesis of AIDS encephalopathy" [1].

During these experiments, Dr. David Mattson, a colleague in the U/R Department of Neurology, provided me with plaque-targeted autopsy and biopsy tissues from 13 MS patients to use as controls. My next application of the two-step ISPCR technique for co-localization of HIV-1 and HHV-6 therefore included these tissues, in addition to our pediatric AIDS and control brain tissues. The results were startling: in almost every one of the MS brain samples, strong periplaque signal for HHV-6 was detected in vast numbers of cells, almost exclusively of oligodendrocytic morphology. This suggested that HHV-6 was strongly associated with demyelination in MS. Furthermore, the fact that HHV-6 was present almost exclusively in oligodendrocytes in MS whereas HIV-1 was mainly found in microglia, macrophages, MGCs, lymphocytes and astrocytes in AIDS tissue, but not in oligodendrocytes, suggested that these two viruses do not interact directly by intracellular co-infection in AIDS brain. These results, obtained in 1997-1998, were written up and submitted to the New England Journal of Medicine. They responded that we did not have enough cases and controls. Therefore, we took some time to accumulate and evaluate a statistically more significant collection of formalin-fixed, paraffin-embedded brain samples from a larger number of neurological disease and control cases.

\section{Our Studies on HIV-1, HHV-6 and JC virus in AIDS, MS, PML and Control Brain Tissues}

During a sabbatical summer at the University of Iowa, learning about astrocytes from Prof. Sean Murphy, I made the acquaintance of Dr. Jose Assouline, who arranged to provide us with formalin-fixed paraffin-embedded brain tissue samples from 13 patients who died from PML, with and without underlying AIDS. In addition to samples from our close neuropathologist collaborators Drs. Sharer (UMDNJ) and James M. Powers (University of Rochester), and also from Drs. Jeanne Bell (Edinburgh), P.G.E. Kennedy (Glasgow) and Catherine Keohane (Cork), this gave me an international collection of tissue blocks from over 30 pediatric and adult HIV-1 brains: one case each of Parkinson's, Alzheimer's, ALS, glioblastoma, cerebrovascular disease and SSPE, and two cases of hypoxia/ischemia, where the cellular morphology was distinctive. It is worth mentioning that these tissues included brain samples from late-stage abortuses, which are the only tissues that are reliably HHV-6 negative. Such tissues are much more difficult to obtain today, in the midst of our epidemic of political correctness.

Now in the laboratory of Dr. Andrew D. Goodman at the University of Rochester, I studied these tissues intensively, using various combinations of two-step ISPCR, in situ hybridization and single and double immunocytochemistry, for nucleic acids and proteins expressed by HIV-1, HHV-6 and JC virus [24]. The results of these studies confirmed that activated HHV-6 was highly prevalent in MS and PML tissues, but was "normal" in AIDS and other neurological disease control tissues without evidence of demyelination. As expected, HIV-1 was present in higher amounts in AIDS tissues than activated HHV-6, but in AIDS tissues HIV-1 was confined to macrophages, microglia, MGCs, lymphocytes and astrocytes, while in MS tissues HHV-6 was present in large numbers of cells, mainly identified as oligodendrocytes, with a few neurons also showing signal. Surprisingly, HHV-6 was present in many more cells than JCV in the PML samples, and often co-localized with JCV, strongly suggesting that the real function of JC virus was to activate, or "rile up", HHV-6 in cells coinfected with the two viruses. We did not have microscopes with software capable of counting signals in cells at that time, so we could not provide exact cell counts for statistical analysis, but the results were so striking that I had then, and still have, great confidence in this interpretation.

\section{Our Studies on Life, Death and Lineage in Glial Cells}

Two other important neuropathological observations were made on these tissues. The first, by my colleague Harris Gelbard, MD and his group [24,25], was that while neurons and microglia and leukocytes frequently showed signs of apoptosis in AIDS and PML brains, using the newly-developed TUNEL and ISEL techniques, astrocytes and oligodendrocytes rarely did, suggesting that cells of glial origin were resistant to virus-induced cell death. This observation was supported by later studies in cultured cells $[7,8]$. The second and most critical work was done on glial precursor cells by Joerg Dietrich in the 
Citation: Blumberg BM (2016) HHV-6, Not JC Virus, Causes Demyelination in PML Connections Between HHV-6, HIV-1 and JC Virus in Multiple Sclerosis, Neuro-AIDS and PML A Commentary and Review Offering Guidelines for Treatment. J Neurol Disord 4: 299. doi: $10.4172 / 2329-6895.1000299$

Page 3 of 6

laboratory of Mark Noble and Margot Mayer-Proschel at Rochester The outstanding feature of Dietrich's studies was that HHV-6 infection of cultured oligodendrocyte progenitor cells did not readily kill these cells. Rather, the cells became hugely swollen and vacuolated, and reverted to expression of GFAP (an immunocytochemical marker for astrocytes in brain tissue and cultured cells) instead of CNPase or galC (markers for oligodendrocytes in brain tissue), or A2B5 (a marker for oligodendrocytic cells in culture). This suggests that HHV-6 infection of oligodendrocytes induces these glial cells to revert to their astrocytic roots, rather than dying. In contrast, oligodendrocytic cells dually infected with HHV-6 and JC virus do undergo apoptosis readily [8].

To visualize this phenomenon properly, it is essential to understand that both astrocytes and oligodendrocytes evolve from O2A progenitor cells [26-28]. These progenitor cells are present in large numbers in the developing brains of children, and remain numerous in adult brains [27-30]. Those glial cells which develop along the oligodendrocytic pathway go on to produce the proteins responsible for myelination of neural tracts [31], while the remainder of the glial progenitor cells go on to become astrocytes, among whose duties is the care and feeding of their brother oligodendrocytes, which must devote most of their metabolism to the production of the myelin proteins. If viral infection does not kill the target cell outright, as is true of HHV-6 in oligodendrocytes, the infection nonetheless strongly degrades the most differentiated functions of the cell [32], which in oligodendrocytes means interfering with the production of myelin proteins. Infection with HHV-6 causes the oligodendrocytes to pull back the extended and extensive processes which feed myelin proteins into the lamellae, and revert to a more basic astrocytic cell type with production of astrocytic cell markers such as GFAP. In PML, co-infection of oligodendrocytes with HHV-6 and JC virus results in the appearance of so-called "bizarre" astrocytes: grossly swollen cells with scalloped edges that stain for the astrocyte marker GFAP. In reality, these cells are dually infected oligodendrocytes caught in the course of pulling back their processes, which are seen as the "spikes" of the scallops.

\section{Is HHV-6 The Cause of All Human Demyelinating Diseases?}

Having once understood that HHV-6 is the probable direct cause of demyelination in MS and in PML, the question occurred to us whether HHV-6 might not be the universal cause of all human demyelinating diseases? After all, HHV-6 has all the qualities required for both causing demyelination and escaping blame for it. It is universally acquired by age 2 ; most infants are infected within the first few days of life, by their mother's kiss, since HHV-6 is carried in the saliva. It does not stand out in epidemiological studies precisely because it is ubiquitous and commensal. Although it does cause roseola, a common disease of infancy, often with a fever and a rash (exanthem subitum), it generally is benign and indolent and people lose sight of the fact that it is highly tropic for oligodendrocytes, where it remains lifelong, generally without causing trouble. However, when it becomes "riled up" by some outside agent or condition such as inflammation, HHV-6 is capable by itself of causing fatal encephalitis [5].

Nonetheless, HHV-6 does not cause demyelination in all neurological diseases. Other potential environmental or host activities are at work in the early white matter lesions of AdrenoLeukodystrophy (ALD), a demyelinating disease thought to be caused by an X-linked genetic defect in the metabolism of very long chain lipids (the movie Lorenzo's Oil captures this disease and its effects perfectly) [33] . We tested brain sections from ALD patients provided by $\mathrm{AB}$ and HW Moser for HHV-6 and other agents [6], and obtained morphologic evidence for CD8 cytotoxic T cells, cytolysis of oligodendrocytes, and CD1-mediated lipid antigen presentation, but HHV-6 was not found in ALD sections by our sensitive two-step ISPCR method or by immunocytochemistry as it had been in MS or PML sections [6]. Thus, a biochemical defect is able to produce a demyelinating disease with neuropathological characteristics similar to MS.

\section{Our Vanishing Presence in Reviews and Laboratory Studies on PML}

Our studies on HHV-6 in the context of PML were first reviewed by Caserta, Mock and Dewhurst in 2006 (members of the Rochester group). At this time, at least two other laboratories were interested in the same problem, one at NIH and the other in Japan. At NIH, experiments were performed by Steve Jacobson's group to investigate the effect on a persistently JC virus-infected astrocytic cell line of exogenously added HHV-6A. The results showed that JC virus gene expression was indeed stimulated by HHV-6 [34], but this was backwards to the way I viewed the problem. In this paper, Jacobson did cite Mock et al. [2]. In Japan, a group headed by Masanori Daibata at Kochi University showed that HHV-6 was activated in PML brain tissue, presumably by JC virus, in line with my results and views $[35,36]$. Unfortunately for me, Daibata's primary interests were whether HHV-6 could become integrated into the human germ line [35-37], and in the microbiota of dermal oncogenesis. His first interest was eventually answered convincingly, in the affirmative, by several groups [35], and his second was answered by Daibata himself with the identification of the variants $\mathrm{MCPyV}$ and human polyoma virus 9 in Japanese patients $[35,36]$.

Surprisingly, Lisa Demeter, who worked with our group in Rochester on studies of antiretroviral drugs against HIV-1, made no mention of our work in her Chapter 134 on PML in Mandell, Douglas and Bennet's textbook Principles and Practice of Infectious Disease [9], thought by many to be the most complete and authoritative textbook on infectious disease. This is understandable, as our work was proceeding contemporaneously with her writing, and the implications of our work were not yet clear. However, no subsequent edition of PPID has included any mention of our papers on MS or PML, nor any mention of the papers by Jacobson or Dibata either, and these omissions should be corrected.

Perhaps the vanishing point for our papers occurred with the otherwise exceptionally fine 2-part review Emerging Viral Infections of the Central Nervous System, by. In the final section of Part 1, Tyler discusses HHV-6 strains A and B in conjunction with Roseola and febrile seizures in children, and as a cause of encephalitis in children and adults, while at the beginning of Part 2 he discusses JC virus in association with PML, pointing to reactivation of latent virus as the cause. Tyler also discussed the early findings that treatment with natalizumab (Tysabri) for MS or Crohn's disease brought on PML at a rate of about 1 case per 1000 treated patients per 18 months of therapy, resulting in its withdrawal (and subsequent re-introduction) to the marketplace. But any role for HHV-6 in PML or MS was entirely omitted.

Subsequent reviews seem to have taken their orientation from PPID and from EVICNS, and focussed exclusively on JC virus as the cause of PML. The current NINDS PML Online Info Page (Sept 11, 2015) speaks of polyoma virus JC and HIV-1, but there is no mention of 
HHV-6. Conversely, a recent review on Human Herpesvirus 6 Infection [38] discusses the fact that there are now 2 recognized strains of HHV-6: "HHV-6B causes the childhood illness roseola infantum, whereas HHV-6A has been isolated mainly in immunocompromised hosts". Salvaggio notes that HHV-6 has been isolated from various bodily tissues, cells and fluids in association with 10 conditions including lymphoma, lymphadenopathy, sarcoidosis, systemic lupus erythematosis, chronic fatigue syndrome, Guillain-Barre syndrome and multiple sclerosis, but makes no mention of PML.

A binary internet search of PubMed for "PML and HHV-6" done in August 2016 showed 16 hits, while a similar search for "PML and JCV" showed 620 hits, a ratio of 38.75. Since some of the hits on PML referred to promyelocyic leukemia, and some of the hits on HHV-6 referred to human polyomavirus 6 or other herpesviruses, the actual ratio is more like 40:1, an indicator of just how strongly attention has focussed on JC virus rather than HHV-6 in PML. Similarly, a binary search for "HHV-6 and MS" gave 154 hits, while if "multiple sclerosis" was substituted for "MS" there were 247 hits, showing that at least there is plenty of interest in the connection between HHV-6 and MS, although most authors are careful to mention that causation is considered controversial. Interestingly, a binary search for "JCV and MS" (or multiple sclerosis) gave 158 (or 183) hits, showing that interest has risen dramatically in the MS-PML connection following the introduction of Tysabri and Gilenya. However, a trinary search for "JCV and HHV-6 and MS" yielded only 9 hits, while a similar search for "JCV and HHV-6 and PML" yielded only 8 hits, demonstrating that the 4-way connection between HHV-6, JC virus, MS and PML has not yet entered the popular consciousness. There have been several recent hits on Mock et al. [2] and on Blumberg et al. [3] in research papers on the website www.ResearchGate.com, but none has yet risen to the level of a review article. It is my hope that this review will help set the record straight.

\section{Conclusions, Significance and Guidelines for Treatment}

One reason why our eight papers [1-8] failed to capture more attention, is that much of the data was obtained in an AIDS setting, while their real impact would eventually be on MS and PML. Another is that the other groups working in this area - there were only 3 or 4 shifted their attention to other problems. But perhaps the greatest problem is that our papers called upon the reader to accept not one, but two paradigm shifts. First, that the true role of JC virus in PML etiology is not that of the demyelinative agent, but rather that of a stimulatory co-factor that "riles up" HHV-6 which is universally present in oligodendrocytes. Second, that the "bizarre astrocytes" which are the hallmark of PML to a neuropathologist, are not astrocytes at all, but rather are grossly swollen, actively HHV-6 infected oligodendrocytes in the process of reverting to their GFAPpositive astrocytic roots.

Today, more than a decade after our studies were performed, there is no approved, specific anti-HHV-6 drug on the market [10].

However, a significant deficit of all current drug trials is that a new drug is always tested as monotherapy by its manufacturer. This is acceptable when the etiologic agent is unknown or controversial, but this review should help to clarify the question of etiology. The significance of this review, therefore, is to emphasize that PML is really due to the interaction of HHV-6 and JC virus in oligodendrocytes, and consequently that treatment options in PML should focus equally on inhibitors of both HHV-6 and JC virus.

Treatment for HIV-1/AIDS only became successful with the development of combined anti-retroviral therapy (cART). The point to cART therapy is to target multiple essential functions of HIV-1 in order to prevent rapid acquisition of resistance. The currently available targets in HIV-1 and some relevant drugs include the viral reverse transcriptase (tenofovir, emtricitabline, efavirenz), the protease (ritonavir+ lopinavir, darunavir, atazanavir) and the integrase (elvitegravir, raltegravir) along with a drug (cobicistat) that acts to inhibit liver enzymes that degrade elvitegravir. In development there are also antagonists of the cell entry cofactor CCR5 (see Wikipedia articles on Managemant of HIV/AIDS and CCR5 receptor antagonist). The WHO- preferred initial regimen as of 2013 included three different RT inhibitors (tenofovir + efavirenz + lamivudine or emtricitabine). The most comprehensive current cocktails against HIV-1 (Stribild ${ }^{\circledR}$ and Genvoya ${ }^{\circ}$ ) use four drugs to target the polymerase (tenofovir + emtricitabine) and the integrase (elitegravir +cobicistat). In PML, since there are two interacting viruses at work, the antiviral cocktail should contain at a minimum two different drugs, one for each virus.

A further and more subtle consideration is that the targeting of multiple functions of HIV-1 was essential because this virus exists as a quasispecies as reported by Eigen, Eigen and Biebricher, Wain-Hobson and Domingo $[11,34,39,40]$. In a quasispecies, the viral "swarm" contains preformed genomic mutations at every genomic position, and thus drug-resistant variants are immediately selected. The HIV-1 swarm is characterized by the presence of a "master" species comprising $50 \%$ or more of the variants in a given genomic location, with other variants present in lower amounts [12]. HIV-1 evolution proceeds by both point mutations and by insertion-deletion type mutations [36]. Quasispecies occur in HIV-1 because the viral RNA polymerase has no editing function, thus the error rate per nucleotide incorporated into a new genome is very high, on the order of 1:104 [41]. Since both JC virus and HHV-6 have DNA genomes and a polymerase with editing functions, their error rate is at least three orders of magnitude lower, on the order of 1:107, but this should not lull us into a false sense of complacency. As noted above, there are two variants of HHV-6, A and B, which are sufficiently different that some think of them as two different viral species, while there are at least six known variants of JC virus, Mad 1-4 [42], and MCPyV and polyomavirus $9[35,36]$. By analogy, there are probably preformed genomic variants of both JC virus and HHV-6 latently infecting oligodendrocytes, perhaps at a level of $1-2 \%$ of the total genomes (a "skewed" swarm, where the master species constitutes the vast majority of the genomes present), and although in lesser profusion than their HIV-1 analogs, these minor but potentially drug resistant variants would also be immediately selected by the use of a single drug for each virus. The bottom line is that four different inhibitors would not be out of line in an anti-PML drug cocktail.

The use of anti-HIV-1 drugs failed to produce neurological improvement in patients with PML, but did prolong their survival. Cidofovir and cytosine arabinoside, which have both anti-herpes and anti-polyomavirus activity, were helpful in one case [43]. Valacyclovir has been tested in MS, but with little success so far [44,45]. The failure of either IV or intrathecal cytarabine to improve survival in PML [46] led us previously to suggest alternative drugs (gancyclovir). Valganciclovir, which is very effective against cytomegalovirus (CMV), might be an improvement. 
Citation: Blumberg BM (2016) HHV-6, Not JC Virus, Causes Demyelination in PML Connections Between HHV-6, HIV-1 and JC Virus in Multiple Sclerosis, Neuro-AIDS and PML A Commentary and Review Offering Guidelines for Treatment. J Neurol Disord 4: 299. doi: $10.4172 / 2329-6895.1000299$

Page 5 of 6

There is now an HHV-6 Foundation dedicated to the treatment of HHV-6-related diseases. The Foundation points out that, in the absence of a drug specific for HHV-6, clinicians usually utilize agents against cytomegalovirus (CMV aka HHV-5, a close relative of HHV-6), such as (val) ganciclovir, cidofovir and foscarnet. Unfortunately, each of these agents has adverse side effects: e.g. ganciclovir poses a risk of hematological toxicity, while foscarnet poses a risk of renal toxicity. In contrast, artesunate, an agent used clinically in the treatment of malaria, surprisingly has shown strong activity against HHV-6 in tissue culture [47], and has proven successful against HHV-6B myocarditis in a child [48] where no serious adverse side effects were noted.

The HHV-6 Foundation mentions four drugs currently under study as treatments that have had limited success in the management of HHV-6: Brincidofovir, (CMX001, by Chimerix in a large trial), Cyclopropavir (by Microbiotics), Isoprinosine and Ampligen. Isoprinosine is a synthetic purine derivative with both immune modulating and antiviral properties [49], while Ampligen (produced by Hemispherx Biopharma Inc), a mismatched double-stranded RNA with broad anti-viral and immunododulatory activites, is currently pursuing FDA approval. There are two anti-herpes drugs under development at Bayer (BAY 57-1293 and BILS 179 BS at Boehringer Ingleheim) which have proven effective against HSV-1 and -2 in mice [50,51]. These drugs target the viral helicase-primase rather than the polymerase, so mixing them with a polymerase inhibitor would conform with the principles of cART. Hexadecylcycloxypropylcidofovir (CMX001) is currently also under study for treating JC virus because it inhibits JC viral replication in human fetal brain cultures (Jiang 2010) [52]. More recently, drugs against potentially All viruses have been invented by Todd Rider and colleagues at MIT's Lincoln Laboratory: called DRACOs (Double-stranded RNA activated Caspase Oligomerizers), these drugs work by combining a dsRNA binding protein with another that induces apoptosis in infected cells [53].

I reiterate that a cocktail of drugs aimed at inhibiting at least two different targets in each virus is likely to be more effective than monotherapy with any of the above drugs used alone, and suggest that since PML is rapidly fatal in the absence of effective treatment, various cocktail mixtures should be tried clinically even before each separate drug gains approval by the FDA. I should also point out that JC virus, with its small genome size ( $\sim 5200$ bases) codes for only six proteins, so it should be easy to find out experimentally which ones stimulate HHV-6 in tissue culture. HHV-6, on the other hand, has a genome size of about 165,000 bases and codes for about 110 viral proteins, so the experiments to see whether and which HHV-6 gene products stimulate JCV will not be so easy. I would nonetheless suggest that since latency in herpesviruses is actively maintained by synthesis of latency transcripts and proteins, these should be investigated first. Finally, I would recommend, as a guess, a four-part anti-PML drug cocktail consisting of valganciclovir, one of the helicase-primase drugs, artesunate, and either a DRACO, or ampligen, or CMX001.

\section{References}

1. Saito Y, Sharer LR, Dewhurst S, Blumberg BM, Hall CB, et al. (1995) Cellular localization of human herpesvirus- 6 in the brains of children with AIDS encephalopathy. J Neurovirol 1: 30-39.

2. Mock DJ, Powers JM, Goodman AD, Blumenthal S, Ergin N, et al. (1999) Association of human herpesvirus 6 with the demyelinative lesions of progressive multifocal leukoencephalopathy. J. Neurovirol 5: 363-373.

3. Blumberg BM, Mock DJ, Powers JM, Ito M, Assouline JG, et al. (2000) The HHV6 paradox: ubiquitous commensal or insidious pathogen? A two-step in situ PCR approach. J Clin Virol 16: 159-178.
4. Goodman AD, Mock DJ, Powers JM, Baker JV, Blumberg BM (2003) Human herpesvirus 6 genome and antigen in acute multiple sclerosis lesions. J Infect Dis 187: 1365-1376.

5. Ito M, Baker JV, Mock DJ, Goodman AD, Blumberg BM, et al. (2000) Human herpesvirus 6-meningoencephalitis in an HIV patient with progressive multifocal leukoencephalopathy. Acta Neuropathol 100: 337-341.

6. Ito M, Blumberg BM, Mock DJ, Goodman AD, Moser AB, et al. (2001) Potential environmental and host participants in the early white matter lesion of adreno-leukodystrophy: morphologic evidence for CD8 cytotoxic T cells, cytolysis of oligodendrocytes, and CD1-mediated lipid antigen presentation. J Neuropathol Exp Neurol 60: 1004-1019.

7. Dietrich J, Blumberg BM, Roshal M, Baker JV, Hurley SD, et al. (2004) Infection with an endemic human herpesvirus disrupts critical glial precursor cell properties. J Neurosci 24: 4875-4883.

8. Mock DJ, Chugh P, Kim B, Proschel C, Dietrich J, et al. (2006) Characterization of specific HHV-6 and cell cycle genes implicated in virus-mediated G1/S cell-cycle arrest of glial precursors. Retrovirology 3 (Suppl 1) S65.

9. Demeter LM (2000) JC, BK and other polyomaviruses: Progressive multifocal leukoencephalopathy. In: Mandell, Douglas and Bennet's principles and practice of infectious diseases, (5thedn), Chapter 134, Churchill Livingston Press p: 1645-1651.

10. Koralnik IJ (2016) Progressive mutifocal leukoencephalopathy: Treatment and prognosis. Www.UpToDate.com Update, Wolters Kluwer.

11. Eigen M (1971) Self-organization of matter and the evolution of biological macromolecules. Naturwissenschaften 58: 465-523.

12. Blumberg BM, Epstein LG, Saito Y, Chen D, Sharer LR, et al. (1992) Human immunodeficiency virus type 1 nef quasispecies in pathological tissue. J Virol 66: 5256-5264.

13. Pruksananonda P, Hall CB, Insel RA, McIntyre K, Pellett PE, et al. (1992) Primary human herpesvirus 6 infection in young children. N Engl J Med 326: 1445-1450.

14. Hall CB, Long CE, Schnabel KC, Caserta MT, McIntyre KM, et al. (1994) Human herpes virus- 6 infection in children. A prospective study of complications and reactivation. N Engl J Med 331: 432-438.

15. Fields BN, Knipe DM, Howley PM (1996) Fields' Virology (3rdedn), Lippincott-Raven, NY. p: 2039.

16. Salahuddin SZ, Ablashi DV, Markham PD, Josephs SF, Sturzenegger S, et al. (1986) Isolation of a new virus, HBLV, in patients with lymphoproliferative disorders. Science 234: 596-601.

17. Challoner PB, Smith KT, Parker JD, MacLeod DL, Coulter SN, et al. (1995) Plaque-associated expression of human herpesvirus 6 in multiple sclerosis. Proc Natl Acad Sci USA 92: 7440-7444.

18. Sanders VJ, Felisan S, Waddell A, Tourtellotte WW (1996) Detection of herpesviridae in postmortem multiple sclerosis brain tissue and controls by polymerase chain reaction. J Neurovirol 2: 249-258.

19. Sharer LR, Saito Y, Epstein LG, Blumberg BM (1994) Detection of HIV-1 DNA in pediatric AIDS brain tissue by two-step ISPCR. Adv Neuroimmunol 4: 283-285.

20. Sharer LR, Saito Y, Da Cunha A, Ung PC, Gelbard HA, et al. (1996) In situ amplification and detection of HIV-1 DNA in fixed pediatric AIDS brain tissue. Hum Pathol 27: 614-617.

21. Saito Y, Sharer LR, Epstein LG, Michaels J, Mintz M, et al. (1994) Overexpression of nef as a marker for restricted HIV-1 infection of astrocytes in post-mortem pediatric central nervous tissues. Neurology 44: 474-481.

22. Lusso P, Ensoli B, Markham PD, Ablashi DV, Salahuddin SZ, et al. (1989) Productive dual infection of human CD4+ T lymphocytes by HIV-1 and HHV-6. Nature 337: 370-373.

23. Ongradi J, Kovesdi V, Nagy K, Matteoli B, Ceccherini-Nelli L, et al. (2011) In vitro and in vivo transactivation of HIV-1 by human herpesvirus 6 . Chapter 11 in HIV-Host Interactions 257-298.

24. Gelbard HA, James JJ, Sharer LR, Perry SW, Saito Y, et al. (1995) Identification of apoptotic neurons in post-mortem brain tissue from 
Citation: Blumberg BM (2016) HHV-6, Not JC Virus, Causes Demyelination in PML Connections Between HHV-6, HIV-1 and JC Virus in Multiple Sclerosis, Neuro-AIDS and PML A Commentary and Review Offering Guidelines for Treatment. J Neurol Disord 4: 299. doi: $10.4172 / 2329-6895.1000299$

Page 6 of 6

pediatric patients with HIV-1 encephalitis and progressive encephalopathy. Neuropathol Appl Neurobiol 21: 208-217.

25. Krajewski S, James HJ, Ross J, Blumberg BM, Epstein LG, et al. (1997) Expression of pro- and anti-apoptosis gene products in brains from paediatric patients with HIV-1 encephalitis. Neuropathol Appl Neurobiol 23: $242-253$.

26. Chang A, Nishiyama A, Peterson J, Prineas J, Trapp BD (2000) NG-2 positive oligodendrocyte progenitor cells in adult human brain and multiple sclerosis lesions. J Neurosci 20: 6404-6412.

27. Dietrich J, Noble M, Mayer-Proschel M (2002) Characterization of A2B5+ glial precursor cells from cryopreserved human fetal brain progenitor cells. Glia 40: 65-77.

28. Lee JC, Mayer-Proschel M, Rao MS (2000) Gliogenesis in the central nervous system. Glia 30: 105-121.

29. Wolswijk G (1998) Chronic stage multiple sclerosis lesions contain a relatively quiescent population of oligodendrocyte precursor cells. J. Neurosci 18: 601-609.

30. Duchala CS, Asotra K, Macklin WB (1995) Expression of cell surface markers and myelin proteins in cultured oligodendrocytes from neonatal brain of rat and mouse: a comparative study. Dev Neurosci 17: 70-80.

31. Warrington AE, Barbarese E, Pfeiffer SE (1992) Stage specific, (O4+GalC-) isolated oligodendrocyte progenitors produce $\mathrm{MBP}+$ myelin in vivo. Dev Neurosci 14: 93-97.

32. Oldstone MB, Sinha YN, Blount P, Tishon A, Rodriguez M, et al. (1982) Virus-induced alterations in homeostasis: alteration in differentiated functions of infected cells in vivo. Science 218: 1125-1127.

33. Moser HW, Raymond GV, Dubey P (2005) Adrenoleukodystrophy: new approaches to a neurodegenerative disease. JAMA 294: 3131-3134.

34. Wain-Hobson S (1994) Retrovirus evolution. In: Domingo E, Parrish CR, Holland JJ (eds). Origin and evolution of viruses, (2ndedn) Elsevier, Oxford, UK 259-278.

35. Imajoh M, Hashida Y, Nemoto Y, Oguri H, Maeda N, et al. (2012) Detection of Merkel cell polyomavirus in cervical squamous cell carcinomas and adenocarcinomas from Japanese patients. Virol J 9: 154.

36. Imajoh M, Hashida Y, Taniguchi A, Kamioka M, Daibata M (2012) Novel human polyomaviruses, Merkel cell polyomavirus and human polyomavirus 9 in Japanese chronic lymphocytic leukemia cases. J Hematol Oncol 5: 25.

37. Pellett PE, Ablashi DV, Ambros PF, Agut H, Caserta MT, et al. (2012) Chromosomally integrated human herpesvirus 6: questions and answers. Rev Med Virol 22: 144-155.

38. Halterman M, Saito Y, Chen B, Reichman R, Frenkel L, et al. (2015) Transmission of HIV-1 during passage through a bottleneck: different evolution of HIV-1 V3 and NEF quasispecies. BAOJ Hiv 1: 1-11.

39. Eigen M, Biebricher CK (1988) Sequence space and quasispecies distribution 211-245. In Domingo E, ahlquist P, Holland JJ (eds) RNA genetics, vol 3. CRC Press, Boca Raton, FL.
40. Domingo E, Sheldon J, Perales C (2012) Viral quasispecies evolution. Microbiol Mol Biol Rev 76: 159-216.

41. Wu W, Blumberg BM, Fay PJ, Bambara RA (1995) Strand transfer mediated by human immunodeficiency virus reverse transcriptase in vitro is promoted by pausing and results in misincorporation. J Biol Chem 270: 325-332.

42. Jensen PN, Major EO (2001) A classification scheme for human polyomavirus JCV variants based on the nucleotide sequence of the noncoding regulatory region. J Neurovirol 7: 280-287.

43. Blick G, Whiteside M, Griegor P, Hopkins U, Gafton T, et al. (1998) Successful resolution of progressive multifocal leukoencephalopathy after combination therapy with cidofovir and cytosine arabinoside. Clin Infect Dis 26: 191-192.

44. Goodman AD, Miller DH (2002) Infections and MS: clinical trials move to center stage. Neurology 58: 7-8.

45. Bech E, Lycke J, Gadeberg P, Hansen HJ, Malmeström C, et al. (2002) A randomized, double-blind, placebo-controlled MRI study of anti-herpes virus therapy in MS. Neurology 58: 31-36.

46. Hall CD, Dafni U, Simpson D, Clifford D, Wetherill PE, et al. (1998) Failure of Cytarabine in progressive multifocal leukoencephalopathy associated with human immunodeficiency virus infection. New Engl J Med 338: 1345-1351.

47. Milbradt J, Auerochs S, Korn K, Marschall M (2009) Sensitivity of human herpesvirus 6 and other human herpesviruses to the broad-spectrum antiinfective drug artesunate. J Clin Virol 46: 24-28.

48. Hakacova N, Klingel K, Kandolf R, Engdahl E, Fogdell-Hahn A, et al. (2013) First therapeutic use of Artesunate in treatment of human herpesvirus 6B myocarditis in a child. J Clin Virol 57: 157-160.

49. Diaz-Mitoma F, Leger C, Miller H, Giulivi A, Frost R, et al. (2003) Comparison of DNA amplification, mRNA amplification, and DNA hybridization techniques for detection of cytomegalovirus in bone marrow transplant recipients. J Clin Microbiol 41: 5159-5166.

50. Crute JJ, Grygon CA, Hargrave KD, Simoneau B, Faucher AM, et al. (2002) Herpes simplex virus helicase-primase inhibitors are active in animal models of human disease. Nat Med 8: 386-391.

51. Kleymann G, Fischer R, Betz UA, Hendrix M, Bender W, et al. (2002) New helicase-primase inhibitors as drug candidates for the treatment of herpes simplex disease. Nat Med 8: 392-398.

52. Jiang XG, Cohen J, Marshall LJ, Major EO (2010) Hexadecyloxypropylcidofovir (CMX001) suppresses JC virus replication in human fetal brain SVG cell cultures. Antimicrob. Agents and Chemother 54: 4723-4732.

53. Rider $\mathrm{T}$ (2011) Broad-spectrum antiviral therapeutics. PLoS ONE 6: e22572. 